DOI: 10.12731/2227-930X-2020-2-65-75

УДК 623.486

\title{
ПОВЫШЕНИЕ ПРОХОДИМОСТИ АВТОМОБИЛЬНОЙ ТЕХНИКИ (БОЕВЫХ КОЛЁСНЫХ МАШИН)
}

\author{
Тухватуллин Б.Т., Левченко Д.В., \\ Ходоркин О.Л., Зольников И.В.
}

В работе рассматриваются некоторые аспекты проходимости как одного из основных эксплуатационно-технических свойств, оказывающих влияние на боевую эффективность применения боевых колёсных машин. Раскрываются основные параметры и показатели проходимости, пути повыпения проходимости, конструкционные решения обеспечивающие высокую проходимость боевых колёсных машин.

Ключевые слова: эксплуатационные свойства; боевая эффективность; подвижность; проходимость; профильная проходимость; опорно-тяговая проходимость.

\section{IMPROVEMENT OF PERFORMANCE OF VEHICLES (COMBAT WHEELS)}

\section{Tukhvatullin B.T., Levchenko D. V., Khodorkin O.L., Zolnikov I.V.}

In mhe paper discusses some aspects of patency as one of the main operational and technical properties that affect the combat effectiveness of the use of military wheeled vehicles. The basic parameters and indicators of cross-country ability, ways to increase cross-country ability, structural solutions providing high cross-country ability of combat wheeled vehicles are revealed.

Keywords: operational properties; combat effectiveness; mobility; maneuverability; profile maneuverability; support and traction maneuverability. 
Под боевой эффективностью образцов вооружения, военной и специальной техники (ВВСТ) подразделений, частей и соединений войск национальной гвардии понимается их способность выполнять основные боевые и служебные задачи [1, с. 17]. Боевые и технические возможности образцов ВВСТ закладываются в их конструкции при проектировании, реализуются при изготовлении и проявляются в процессе эксплуатации.

Характер выполнения основных боевых и служебных задач образцами ВВСТ определяется исходя из их целевого предназначения. Однако общая характеристика боевых свойств образцов ВВСТ, обуславливающая их боевую эффективность, определяется такими боевыми свойствами, как:

- огневая мощь - способность поражать боевую технику и живую силу противника огнём своего вооружения;

- защищённость - способность противостоять современным средствам поражения;

- подвижность - способность наиболее выгодно использовать внешние условия и приспосабливаться к особенностям процесса боя или служебной задачи за счёт перемещения на местности.

Подвижность - одно из главных боевых свойств образца ВВСТ, характеризующиеся способностью образца к переходу из одного района в другой или от одного рубежа к другому за определённое время. Так же подвижность можно представить, как способность образца ВВСТ к управляемому передвижению с определённой скоростью в различных условиях движения и преодолению препятствий и заграждений. Подвижность является комплексным боевым свойством, составляющими которого являются эксплуатационные свойства быстроходность, манёвренность и проходимость.

Под эксплуатационными свойствами образцов ВВСТ понимается совокупность качественных и количественных показателей, характеризующих приспособленность ко всем аспектам их эксплуатации [2, с. 54]. 
Проходимость является одним из эксплуатационно-технических свойств боевых колёсных машин (БКМ) и важной составляющей подвижности.

Проходимость определяет предельные возможности машины по обеспечению движения в заданных условиях, т. е. граничные условия между возможностью и невозможностью движения, т.е. показатель проходимости П, который является разностью между силой тяги двигателя, реализуемой на колёсах и силой сопротивления движению со стороны опорной поверхности должен быть больше ноля при условии, что скорость машины также больше ноля [1, с. 35].

$\Pi=\mathrm{P}_{\text {дв }}-\mathrm{P}_{\text {сопр }}>0$ при $\mathrm{V}>0$, где:

П - показатель проходимости;

$\mathrm{P}_{\text {дв }}$ - сила тяги двигателя, реализуемая на колёсах;

$\mathrm{P}_{\text {сопр }}$ - сила сопротивления движению со стороны опорной поверхности;

$\mathrm{V}$ - скорость движения машины.

Итак, проходимость - это свойство машины преодолевать препятствия и двигаться по труднопроходимым грунтам и снегу на грани потери подвижности, это предельные возможности машины двигаться вне дорог, преодолевая: вертикальные препятствия (стенки, пороги); горизонтальные препятствия (канавы, окопы, траншеи и т. п.); местные препятствия (пни, камни, выступы, валуны и пр.); узкие извилистые участки (лесные, горные дороги, объезд воронок и т. д.); крутые подъемы; мягкий грунт (песок, пашня, снег); твердый, но скользкий грунт; водные препятствия.

О способности преодоления машиной тех или иных сопротивлений или препятствий судят по её профильным (геометрическим) и опорно-тяговым параметрам проходимости.

Профильная проходимость определяет возможность машины преодолевать неровности, препятствия и вписываться в заданную полосу движения [3, с. 5].

Оценочными параметрами профильной проходимости являются (рис. 1): 
- максимальные углы преодолеваемого подъема и косогора (углы продольной $\boldsymbol{\alpha}_{\text {п }}$ и поперечной $\boldsymbol{\alpha}_{\mathbf{\kappa}}$ устойчивости);

- углы переднего $\boldsymbol{\alpha}_{\mathbf{c}}$ и заднего $\boldsymbol{\beta}_{\mathrm{c}}$ свеса машины;

- продольный $\mathbf{R}_{\text {пр }}$ и поперечный $\mathbf{R}_{\text {пп }}$ радиус проходимости;

- дорожный просвет $\mathbf{h}_{\text {п }}$;

- коэффициент совпадения следов передних и задних колес Кс;

- высота и ширина преодолеваемых препятствий.

\section{Параметры профильной проходимости боевых колесных машин}

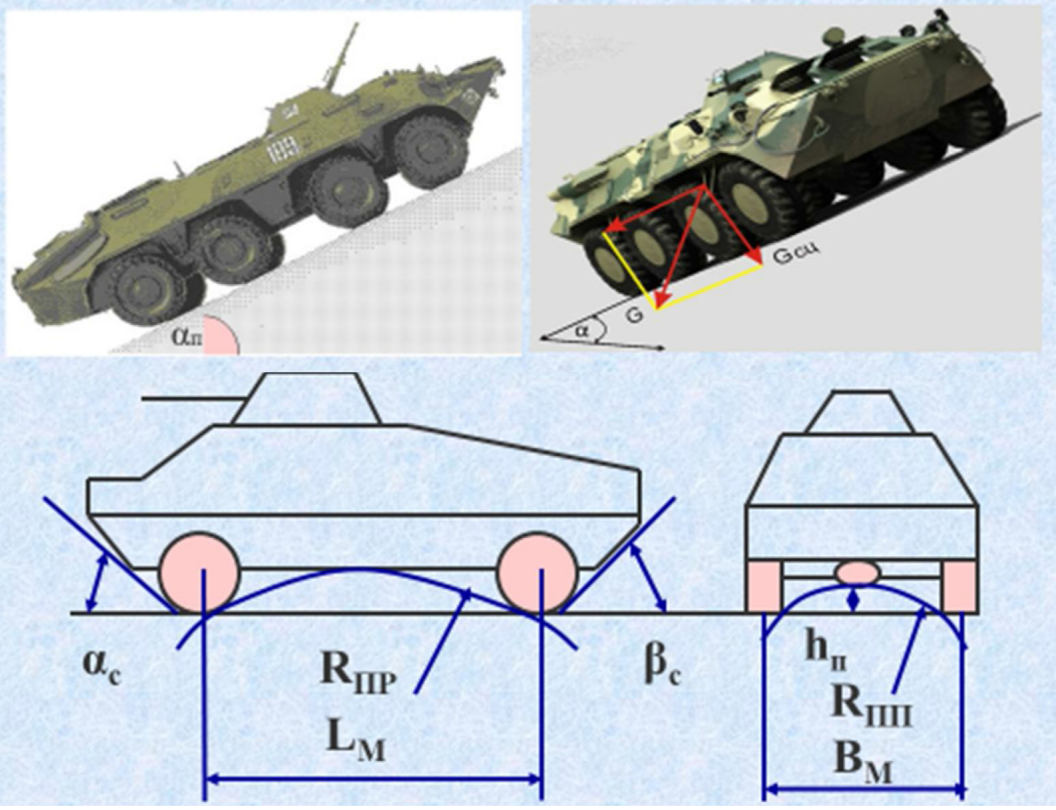

Рис. 1. Параметры профильной проходимости боевых колёсных машин

Опорно-тяговая проходимость определяет возможность машины двигаться в ухудшенных дорожно-грунтовых условиях.

Оценочными параметрами опорно-тяговой проходимости являются: 
- величина наибольшего тягового усилия;

- максимальная скорость движения в рассматриваемых условиях;

- коэффициент сопротивления качению, позволяющий оценить экономичность движения;

- глубина колеи, образующейся за машиной;

- среднее удельное давление на грунт.

В зависимости от способности колесных машин двигаться в условиях плохих дорог и бездорожья они делятся на машины обычной, повышенной и высокой проходимости. К машинам обычной проходимости относятся машины, предназначенные для использования только на автомобильных дорогах (шоссейных и грунтовых).

Их конструктивными особенностями являются привод не на все колеса (только к задним или передним), применение шин с шоссейным рисунком протектора, применение только простых дифференциалов, передаточные числа в трансмиссии подбираются так, чтобы машина могла преодолевать суммарное сопротивление $\psi=0,35 \ldots 0,40$ (ЗиЛ-130, ГАЗ-53) [3, с. 4].

К машинам повышенной проходимости относятся такие, которые имеют привод ко всем колесам. Они имеют раздаточную коробку с понижающей передачей, могут иметь систему регулирования давления воздуха в шинах, самоблокирующиеся дифференциалы, лебедку. Эти машины предназначены для комбинированного использования как на дорогах, так и вне дорог (ГАЗ-3308, ЗиЛ-4334-20, УАЗ-3151, КамАЗ-4310, Урал-4320).

Машинами высокой проходимости называют такие, которые предназначены для использования преимущественно в условиях бездорожья, способные преодолевать участки мягкого грунта, водные преграды, геометрические препятствия. Эти машины отличаются специальной компоновкой, имеют движитель 6х6, 8x8 или комбинированный, обязательно оснащены системой регулирования давления воздуха в шинах, самоблокирующимися дифференциалами, лебедкой, средствами для обеспечения движения на воде (БТР, БРДМ, БАЗ-5921). 
Путями повышения проходимости колесных машин являются:

1. Увеличение клиренса машины (исключить задевание корпуса за грунт);

2. Обеспечить подвод крутящего момента ко всем колесам в соответствии с их сцеплением с грунтом (для этого все колеса должны быть ведущими, а связь в трансмиссии должна быть блокированной, чтобы исключить буксование одного или нескольких колес);

3. Подбор шин (для максимального использования сцепных свойств грунта);

4. Изменение давления внутри шин (для снижения сопротивления качению колес);

5. Оптимальное распределение нагрузки на оси (снижение удельного давления колес на грунт);

6. Оптимальная конструкция движителя (число, схема размещения колес, размеры и форма шин, конструкция протектора).

Основной боевой колёсной машиной, находящейся на вооружении в частях и подразделениях ВНГ РФ, является БТР-80 и его последующие модификации БТР-82, БТР-82А, БТР-82АМ [5, с. 17].

В конструкции БТР-80 применены следующие конструкционные решения, повышающие проходимость машины:

1. Выбраны оптимальные соотношения величин дорожного просвета (клиренс), углов профильной проходимости (углы свеса), радиусов проходимости, углов устойчивости.

2. Применена многоосная схема компоновки трансмиссии с раздаточной коробкой, с блокирующимся межосевым дифференциалом с приводом на все колеса. Применение многоосной схемы компоновки с приводом на все колеса позволяет значительно снизить удельное давление на грунт, общее сопротивление движению, так как основные потери на колееобразование приходятся на передние колеса, остальные колеса движутся по уплотненному грунту, имея лучшее сцепление с грунтом (рис. 2). 


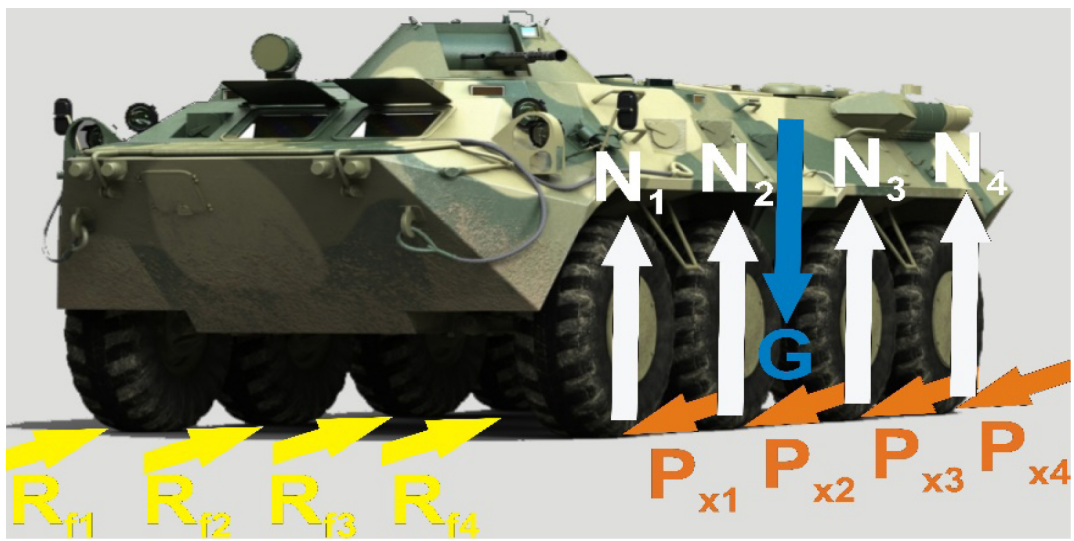

Рис. 2. Распределение нормальной реакции грунта от действия силы тяжести, тяговой силы и сил сопротивления качению БТР-80

3. Применена двойная разнесенная главная передача с самоблокирующимся дифференциалом. Двойная разнесённая главная передача обеспечила реализацию большого передаточного числа при малых габаритах и весе центрального редуктора, так как позволяет разгрузить коническую передачу и карданную передачу от больших крутящих моментов, и, следовательно, сделать эти узлы надежными, компактными и сравнительно малой массы, они применяются на колесных машинах высокой проходимости, у которых должен быть большой дорожный просвет. Главная передача состоит из центрального конического редуктора и двух цилиндрических бортовых редукторов.

4. Применение многоосной схемы компоновки позволяет преодолевать окопы, траншеи и рвы шириной до 2 метров (рис. 3).

5. Применена двойная разнесенная главная передача с самоблокирующимся дифференциалом. Двойная разнесённая главная передача обеспечила реализацию большого передаточного числа при малых габаритах и весе центрального редуктора, так как позволяет разгрузить коническую передачу и карданную передачу от больших крутящих моментов, 
и, следовательно, сделать эти узлы надежными, компактными и сравнительно малой массы, они применяются на колесных машинах высокой проходимости, у которых должен быть большой дорожный просвет. Главная передача состоит из центрального конического редуктора и двух цилиндрических бортовых редукторов.
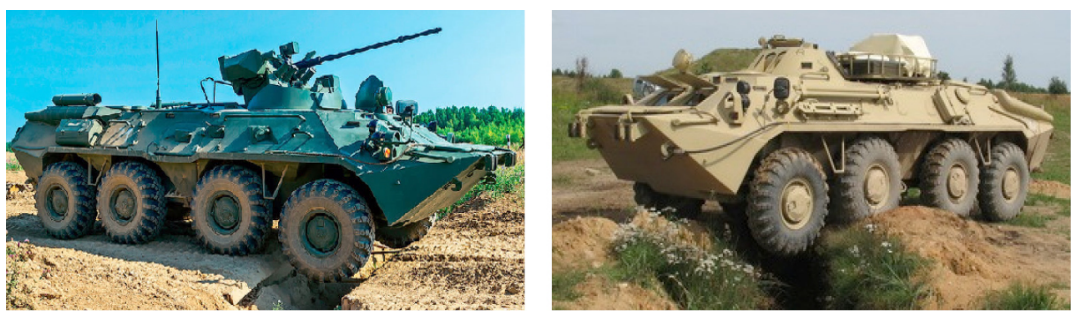

Рис. 3. Преодоление БТР-80 окопов и траншей

6. Применены шины высокой проходимости.

7. Применена система регулирования давления в шинах.

8. Применено средство для самовытаскивания, лебедка.

9. Применено средство для преодоления водных преград на плаву.

Таким образом, анализ конструкционных решений, применённых для повышения проходимости БТР-80 позволяет сделать вывод, что БТР-80 является боевой колёсной машиной высокой проходимости способной двигаться по дорогам и вне дорог, преодолевать естественные и искусственные препятствия, труднопроходимые болотистые, сыпучие грунты, глубокий снежный покров, водные преграды.

\section{Список литературы}

1. Управление эксплуатацией вооружения и военной техники. Учебник. М.: Издание академии, 2004.

2. Эксплуатация бронетанкового вооружения и техники. Учебник. М.: ВИ, 1989.

3. ГОСТ 22653-77 Автомобили. Параметры проходимости. Термины и определения. М.: ГКС СМ СССР, 1978. 
4. ГОСТ 26442-85 Автомобили многоцелевого назначения. Параметры проходимости и методы их определения. М.: ГКС СМ СССР, 1985.

5. Бронетранспортёр БТР-80. Техническое описание и инструкция по эксплуатации (ТО и ИЭ). М.: ВИ, 2001.

\section{References}

1. Upravlenie ekspluatatsiey vooruzheniya i voennoy tekhniki [Management of the operation of weapons and military equipment]. Textbook. M.: Academy publication, 2004.

2. Ekspluatatsiya bronetankovogo vooruzheniya i tekhniki [The operation of armored weapons and equipment]. Textbook. M.: VI, 1989.

3. GOST 22653-77 Cars. Traffic parameters. Terms and Definitions. M.: SCS SM USSR, 1978.

4. GOST 26442-85 Multi-purpose vehicles. Terrain parameters and methods for their determination. M.: SCS SM USSR, 1985.

5. Armored personnel carrier BTR-80. Technical description and instruction manual (maintenance and IE). M.: VI, 2001.

\section{ДАННЫЕ ОБ АВТОРАХ}

Тухватуллин Булат Талирович, доцент кафедры автомобилей, бронетанкового вооружения и техники, кандидат педагогических наук

Федеральное государственное казенное военное образовательное учреждение выстего образования "Новосибирский военный институт им. генерала армии И.К. Яковлева войск наџиональной гвардии Российской Федераџии” Ключ-Камьпшенское плато 6/2, г. Новосибирск, 630114, Российская Федераџия bulat54@mail.ru

Левченко Дмитрий Владимирович, старший преподаватель кафедры автомобилей, бронетанкового вооружения и техники, кандидат педагогических наук.

Федеральное государственное казенное военное образовательное учреждение высшего образования "Новосибирский воен- 
ный институт им. генерала армии И.К. Яковлева войск национальной гвардии Российской Федераџии” Ключ-Камышенское плато 6/2, г. Новосибирск, 630114, Российская Федераџия 6871751@mail.ru

Ходоркин Олег Леонидович, профессор кафедры автомобилей, бронетанкового вооружения и техники, доцент НВИ войск национальной гвардии. Федеральное государственное казенное военное образовательное учреждение выстего образования "Новосибирский военный институт им. генерала армии И.К. Яковлева войск нащиональной гвардии Российской Федераџии” Ключ-Камьшенское плато 6/2, г. Новосибирск, 630114, Российская Федерация tankist1963@gmail.com

Зольников Игорь Владимирович, доцент кафедры технической подготовки.

ПВИ войск наџиональной гвардии.

ФГК ВОУВО «Пермский военный институт войск наџиональной гвардии Российской Федерации»

Гремячий Лог, 1, г. Пермь, 130114, Российская Федераџия bulat54@mail.ru

\section{DATA ABOUT THE AUTHORS}

Tukhvatullin Bulat Talirovich, Associate Professor of the Department of Automobiles, Armored Weapons and Equipment, Candidate of Pedagogical Sciences

Novosibirsk Military Institute named after General of the Army I.K. Yakovleva troops of the National Guard of the Russian Federation

6/2, Kluch-Kamyshenskoe plateau, Novosibirsk, 630114, Russian Federation

bulat54@mail.ru

ORCID: 0000-0002-1573-8548 
Levchenko Dmitry Vladimirovich, Senior Teacher of the Department of Cars, Armoured Weapons and Equipment, Candidate of Pedagogical Sciences

Novosibirsk Military Institute named after General of the Army I.K. Yakovleva troops of the National Guard of the Russian Federation

6/2, Kluch-Kamyshenskoe plateau, Novosibirsk, 630114, Russian Federation

6871751@mail.ru

ORCID: 0000-0003-0688-7311

Khodorkin Oleg Leonidovich, Professor of the Department of Cars, Armoured Weapons and Equipment, Associate Professor Novosibirsk Military Institute named after General of the Army I.K. Yakovleva troops of the National Guard of the Russian Federation

6/2, Kluch-Kamyshenskoe plateau, Novosibirsk, 630114, Russian Federation tankist1963@gmail.com

Zolnikov Igor Vladimirovich, Associate Professor of the Department of Technical Training Perm Military Institute of the National Guard of the Russian Federation

1, Gremichy Log 1, Perm, 130114, Russian Federation bulat54@mail.ru 